\title{
COMPARISON BETWEEN EULERIAN AND VOF MODELS FOR TWO-PHASE FLOW ASSESSMENT IN VERTICAL PIPES
}

\author{
COMPARACIÓN DE LOS MODELOS EULERIANO Y VOF PARA EVALUACIÓN \\ DE FLUJO BIFÁSICO EN TUBERÍAS VERTICALES
}
COMPARAÇÃO DOS MODELOS EULERIANO E VOF PARA AVALIAÇÃO DE ESCOAMENTO BIFÁSICO EM TUBULAÇÕES VERTICAIS

\author{
Esteban Guerrero $^{1 *}$, Felipe Muñoz ${ }^{1}$ and Nicolás Ratkovich ${ }^{1}$ \\ 'Universidad de los Andes, Bogotá D.C., Colombia \\ e-mail: e.guerrero911@uniandes.edu.co
}

(Received: Apr. 04, 2016; Accepted: Aug. 24, 2017)

\begin{abstract}
T The appropriate characterization of the two-phase flow has been recently considered as a topic of interest at industrial level. The Computational Fluid Dynamics (CFD) is one of the techniques used for this analysis. Commonly, the Volume Of Fluid (VOF) model and the Eulerian model are used to model the two-phase flow. The mathematical formulations of these models cause differences in their convergence, computational time and accuracy. This article describes the differences between these two models for applications in the two-phase upward-flow. In order to accomplish this objective, the CFD models were validated with experimental results. This study modeled six experiments with an orthogonal (butterfly) grid. As a result, the Eulerian model shows mean square errors (13.86\%) lower than the VOF model (19.04\%) for low void fraction flows $(<0.25)$. Furthermore, it was demonstrated that Eulerian model performance is independent from grid, spending less computational time than the VOF model. Finally, it was determined that only the VOF model predicts the pattern flow.
\end{abstract}

Keywords: CFD, Two-phase flow, Void fraction, Flow patterns

How to cite: Guerrero, Esteban., Muñoz, Felipe., Ratkovich, Nicolas. (2017). Comparison between Eulerian and VOF models for two-phase flow assessment in vertical pipes. CT\&F - Ciencia, Tecnología y Futuro, 7(1), 73 - 84.

${ }^{*}$ To whom correspondence should be addressed 


\title{
RESUMEN
}

\begin{abstract}
T a correcta caracterización del flujo bifásico se ha vuelto un tema de interés a nivel industrial. La mecánica de fluidos computacional (CFD, por sus siglas en inglés) es una de las técnicas utilizadas para estos análisis. Comúnmente se utiliza en esta herramienta el modelo de volumen de fluido (VOF, por sus siglas en inglés) y modelo Euleriano. La formulación matemática de estos modelos genera diferencias en su convergencia, exactitud y desempeño computacional. Este trabajo pone en evidencia las diferencias de estos dos modelos para aplicaciones de flujo bifásico en dirección vertical. Con el fin de llevar a cabo este objetivo se debe validar estos modelos con resultados experimentales. En este proyecto se realizó la modelación de seis experimentos haciendo uso de un mallado tipo ortogonal (mariposa). Como resultado el modelo Euleriano presenta un error cuadrático medio (13.86\%) inferior al modelo VOF (19.04\%) para flujos con baja fracción de vacío $(<0.25)$. Por otro lado, se evidenció que el modelo Euleriano es independiente de la malla permitiendo un tiempo de simulación menor al del modelo VOF. Finalmente, se determinó que el modelo VOF permite predecir el patrón de flujo a diferencia del modelo Euleriano.
\end{abstract}

Palabras clave: CFD, Flujo bifásico, Fracción de vacío, Patrones de flujo.

\section{RESUMO}

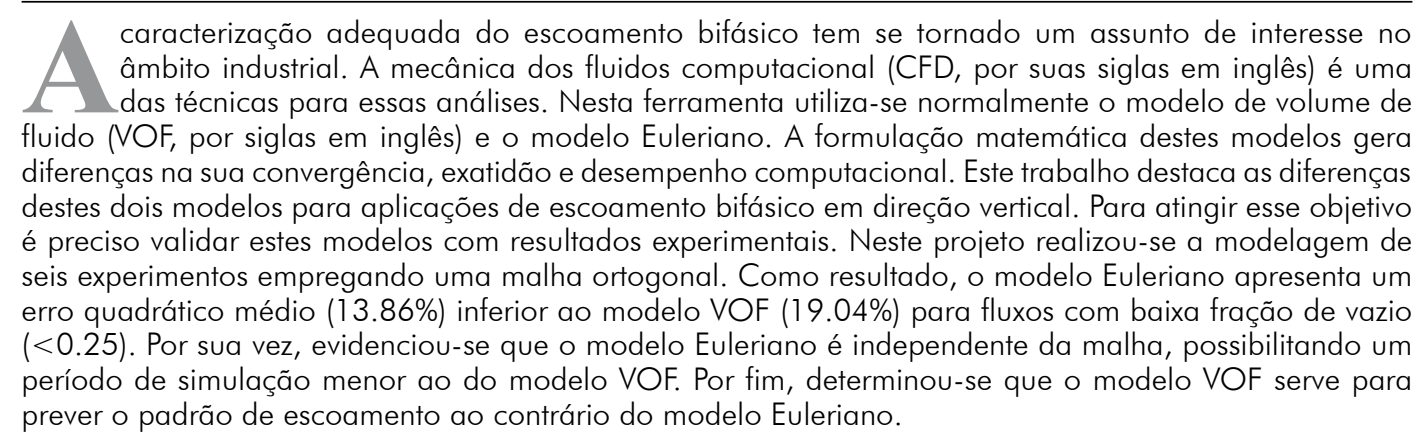

Palavras-chave: CFD, Escoamento bifásico, Fração de vazio, Padrões de fluxo. 


\section{INTRODUCTION}

The multiphase flow, specifically the gas-liquid twophase flow, is an operating condition found in different types of industries. It appears in systems of energy generation, mass transportation, heat transfer, equipment for separation and reaction processes, and equipment for environmental control (Ishii \& Hibiki, 2011).

The nuclear and petroleum industries mainly work with the gas-liquid two-phase flow in their processes. The former, works with this phenomenon in the boiling water or pressurized water nuclear reactors used for the generation of electrical power. The latter, confronts the multiphase flow during oil and gas production in vertical, horizontal and inclined pipes. Furthermore, the two-phase flow appears when well production is enhanced by steam, water or gas injection (Zhang, Wang, Sarica \& Brill, 2003). As a consequence, the correctly operation of these processes is fixed to the variables that describe the gas-liquid two-phase flow. The variation in the volume fractions of the two-phase flow varies from a discontinuous production to a shutdown of the process (Abdulkadir, 2011). For that reason, characterization of the gas-liquid two-phase flow is essential to avoid operating problems.

Different techniques are used to determine the gas-liquid two-phase flow. Experimental methods measure important parameters like local void fraction, bubble size and phase velocities. However, every instrument has advantages and disadvantages in their cost, intrusiveness and resolution (Da Silva, 2008). There is no a cheap non-intrusive multiphase measuring instrument giving the best resolution (Sharaf et al., 2011). Other predictive methods are the empirical and semi-empirical correlations. Woldesemayat and Ghajar (2008) listed and compared 68 void fraction correlations. Nevertheless, all these correlations were formulated for specific flow patterns, inclinations and operating conditions. As a consequence, the two-phase flow models present incorrect predictions when they are extrapolated. Finally, Computational Fluid Dynamic (CFD) is a useful technique to predict the two-phase flow behavior under any condition.

The CFD (model) is capable of simulating the two-phase flow by using different physical models.
Wachem \& Almstedt (2003) conducted a review of the mathematical formulation for CFD models to predict the behavior of the fluid-fluid flow and solid-fluid flow. For the liquid-gas two-phase flow, researches mainly used the Eulerian model (Krishna, Urseanu, van Baten \& Ellenberger, 1999; Ahmai \& Al-Makky, 2014; Shang, 2015) or the Volume of Fluid (VOF) model which is an Eulerian approach (Anglart \& Podowski, 2001; Fang, David, Rogacs \& Goodson, 2010; Abdulkadir, 2011). Additionally, vertical flows have been analyzed using both CFD models (Abdulkadir, 2011; Shang, 2015). Nevertheless, these researches did not stablish a selection criterion for both models. This study demonstrates the differences between the Eulerian model and the VOF model for the two-phase flow assessment in vertical pipes. Models comparison will analyze accuracy, distinguishable phases and computational performance. Finally, it proposes an innovative criteria for the selection of the multiphase flow model on CFD simulations.

\section{THEORETICAL FRAME}

The analyses of the CFD results take into account the hydrodynamic of the two-phase flow. The previous behavior is called the flow patterns. This section explains the possible flow patterns that are acquired in a vertical pipe configuration at different phase velocities. Furthermore, the analysis is easier if Eulerian and VOF models differences are understood, as shown in the mathematical formulation for each model.

\section{Flow patterns}

The phase configurations in vertical pipes are: bubbly flow, slug flow, churn flow, annular flow and mist flow. Previously these are listed from low velocity to high velocity. Moreover, an increase in the gas flow is one of the ways that transitions between patterns occur. By increasing gas velocity in a bubbly flow, small bubbles coalesce to form the Taylor bubbles in slug flow. Churn flow is an instable slug flow resulting from raising the gas velocity. Annular flow appears when gas flow increases, creating an interface stress larger than the effects of gravity. As a consequence, liquid phase is thrown out of the center of the pipe (Thome, 2004). The flow pattern appearances are shown in Figure 1. A mist flow has the same configuration as a bubbly flow except that their phases are inverted (Abdulkadir, 2011). 


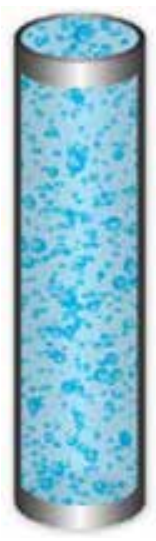

(a)

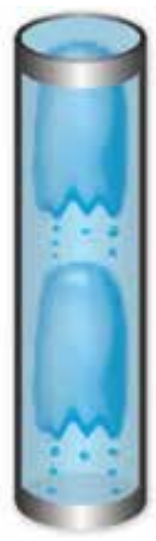

(b)

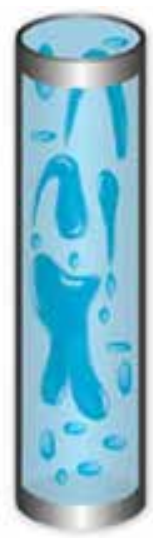

(c)

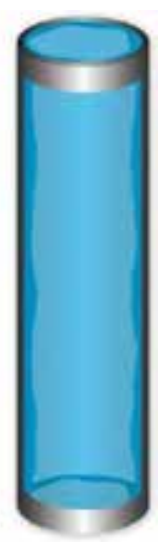

(d)
Figure 1. Flow patterns in vertical pipes. a) Bubbly \& mist flow. b) Slug flow. c) Churn flow. d) Annular flow. Source: (Bratland, 2010).

Transport mechanisms are different in pipes with diameters longer than $50 \mathrm{~mm}$. Consequently, different flow regimes appear (Sharaf \& Luna-Ortiz, 2014). Hence, the pipe diameters modeled in this study are about $50 \mathrm{~mm}$. Furthermore, a flow pattern map for upward flow in a $50 \mathrm{~mm}$ diameter tube is used to predict flow patterns (Hewitt, Delhaye \& Zuber, 1986). Figure 2 shows the map mentioned before.

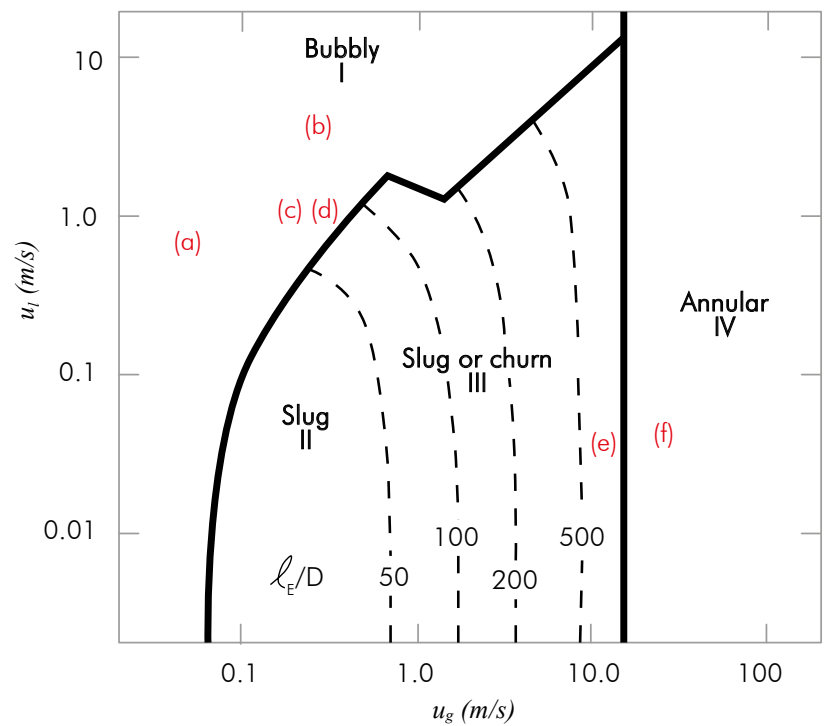

Figure 2. Experimental conditions plotted on Hewitt et al. (1986) flow pattern map.

\section{Mathematical models}

The gas-liquid two-phase flow involves transport of momentum, mass and heat. Nevertheless, heat transfer is omitted, setting the assumption that temperature is constant and uniform in the whole pipe. Hence, Eulerian and VOF models only consider mass and momentum transfers. The mathematical formulation for both physic models are detailed in this section.

\section{Eulerian model}

This method analyzes each phase using one equation for each transport phenomenon. Equations (1) and (2) show the conservation of mass and momentum for phase i (Siemens, 2014).

$\frac{\partial}{\partial t}\left(\alpha_{i} \rho_{i}\right)+\nabla \cdot\left(\alpha_{i} \rho_{i} \bar{u}_{l}\right)=0$

$\frac{\partial}{\partial t}\left(\alpha_{i} \rho_{i} \bar{u}_{l}\right)+\nabla \cdot\left(\alpha_{i} \rho_{i} \bar{u}_{l} \bar{u}_{l}\right)=-\alpha_{i} \nabla P+\alpha_{i} \rho_{i} g+\nabla\left[\alpha_{i}\left(\tau_{i}+\tau_{i}^{t}\right)+M_{i}\right.$

Additionally, the equation (3) must be achieved.

$\Sigma M_{i}=0$

For the previous equations $\alpha$ is the void fraction, $u$ is the superficial velocity, $g$ is the gravity, $P$ is the pressure, $\tau$ is the molecular stress, $\tau^{t}$ is the turbulent stress, $\rho$ is the density and $M_{i}$ represents the momentum transfer in the interface. Furthermore, Eulerian model requires specifying the bubble's gas size. Therefore, the discontinuous phase solution is an agglomerate of these bubbles (Siemens, 2014).

\section{$\underline{\text { VOF model }}$}

As a difference, this method analyzes all phases using a unique equation for each transport phenomenon. Equations (4) and (5) show the conservation of mass and momentum respectively (Abdulkadir, 2011).

$$
\begin{aligned}
& \frac{\partial}{\partial t}+\nabla \cdot(\rho \bar{u})=0 \\
& \frac{\partial}{\partial t}(\rho \bar{u})+\nabla \cdot(\rho \bar{u} \bar{u})=-\nabla P+\rho g+\nabla\left(\tau+\tau^{t}\right)
\end{aligned}
$$

Density and viscosity are calculated as a function of the volume fraction, as shown in the Equations (6) and (7), respectively.

$$
\rho=\sum_{i} \rho_{i} \alpha_{i}
$$

$\mu=\sum_{i} \mu_{i} \alpha_{i}$ 
The VOF model adds an additional equation solving the interfaces. It uses a continuity equation as a function of the volume fractions as shown in the Equation (8). Consequently, this method does not require specifying the bubble gas size (Abdulkadir, 2011).

$$
\frac{\partial \alpha_{i}}{\partial t}+\bar{u} \nabla\left(\alpha_{i}\right)=0
$$

Differences between both models enable simulations with different accuracy, distinguishable phases and computational performance. Therefore, a methodology is established to study this problem.

\section{Turbulence model}

The gas-liquid two-phase flow has a turbulent dynamic which has to be taking account in the CFD models. In this research, the $\mathrm{k}-\varepsilon$ turbulence model was used to close the consecutive equations for both models. Equations (9) and (10) show the PDE equations describing this model (Ratkovich, Majumder \& Bentzen, 2013).

$\rho u_{j} \frac{\partial k}{\partial x_{j}}=\frac{\partial k}{\partial x_{j}}\left(\frac{\mu t}{\sigma_{k}} \frac{\partial k}{\partial x_{j}}\right)+\mu_{t} \frac{\partial u_{j}}{\partial x_{i}}\left(\frac{\partial u_{i}}{\partial x_{j}}+\frac{\partial u_{j}}{\partial x_{i}}\right)-\rho \varepsilon$

$\rho u_{j} \frac{\partial \varepsilon}{\partial x_{j}}=\frac{\partial}{\partial x_{j}}\left(\frac{\mu_{t}}{\sigma_{\varepsilon}} \frac{\partial \varepsilon}{\partial x_{j}}\right)+C_{1} \mu_{t} \frac{\varepsilon}{k} \frac{\partial u_{j}}{\partial x_{j}}\left(\frac{\partial \mu_{i}}{\partial x_{j}}+\frac{\partial \mu_{j}}{\partial x_{j}}\right)-C_{2} \frac{\varepsilon}{k} \rho \varepsilon$

The new two variables correspond to the turbulent kinetic energy $(k)$ and the dissipation rate $(\varepsilon)$. The constants values of $\sigma_{\varepsilon}, \sigma_{k}, C_{1}$ and $C_{2}$ are 1.2, 1.0, 1.44 and 1.9, respectively. Finally, the turbulence effect on the viscosity (turbulent viscosity, $\mu_{t}$ ) has to be involved in the conservative equations using the effective viscosity $\left(\mu_{e f f}\right)$ as shown in the equation (11).

$u_{e f f}=u+u_{t}$

\section{METHODOLOGY}

This section describes the modeling study procedure. First, the test matrix and facilities geometries are presented. Second, it explains the mesh generation and selection criterion. Finally, the time-step is selected by the Courant-Friedrich-Lévy condition (CFL criterion).

\section{Test matrix}

The CFD models performance in the two-phase flow assessment were validated by experimental results. Data was obtained by different authors: Sun et al. (2004), Krepper, Lucas \& Prasser (2005) and Westende (2008). Experiments were replicated using the CFD software STAR-CCM+ v9.02 from Siemens. Operating conditions and facilities geometries are described in Table 1 , where $u_{i}$ is the superficial velocity of phase $i, z$ is the pipe height and $\mathrm{z} / \mathrm{D}$ describes the measurement tool location in the pipe. Each studied case was developed at atmospheric pressure.

Figure 2 shows the experimental conditions plotted on Hewitt et al. (1986) flow pattern map. The study cases location on Figure 2 predicted that the experimental data is the bubbly flow and the annular flow. Therefore, this project studied the two-phase flow with low and high void fractions. The CFD prediction is used as the variable average, as the solution obtains a steady signal.

\section{Mesh generation}

The CFD solution method requires a grid to solve the partial differential equations of both models. Mesh dimensions and arrangement may create a variety of grids for the same geometry. However, the solution convergence, accuracy and velocity depend upon the mesh quality. Hernandez, Abdulkadir \& Azzopardi

Table 1. Geometries and operating conditions

\begin{tabular}{|c|c|c|c|c|c|c|}
\hline Case & $\mathrm{u}_{\mathrm{I}}(\mathrm{m} / \mathrm{s})$ & $u_{g}(m / s)$ & Sensor (z/D) & Author & Diameter (m) & Length $(m)$ \\
\hline A & 0.6150 & 0.049 & 51 & \multirow{2}{*}{$\begin{array}{l}\text { Sun et al. } \\
(2004)\end{array}$} & \multirow{2}{*}{0.0508} & \multirow{2}{*}{3.81} \\
\hline B & 3.4580 & 0.318 & 51 & & & \\
\hline C & 1.0000 & 0.220 & 60 & \multirow{2}{*}{$\begin{array}{l}\text { Krepper et al. } \\
(2005)\end{array}$} & \multirow{2}{*}{0.0512} & \multirow{2}{*}{4.00} \\
\hline $\mathrm{D}$ & 1.0000 & 0.340 & 60 & & & \\
\hline$E$ & 0.0394 & 12.200 & 39 & \multirow{2}{*}{$\begin{array}{c}\text { Westende } \\
(2008)\end{array}$} & \multirow{2}{*}{0.0500} & \multirow{2}{*}{8.00} \\
\hline $\mathrm{F}$ & 0.0411 & 21.200 & 100 & & & \\
\hline
\end{tabular}


(2010) determined that the best mesh distribution for pipes is the orthogonal grid (also known as butterfly shape gird). Figure 3 illustrates the grid distribution mentioned before.

The grid presented in Figure 3 was associated with

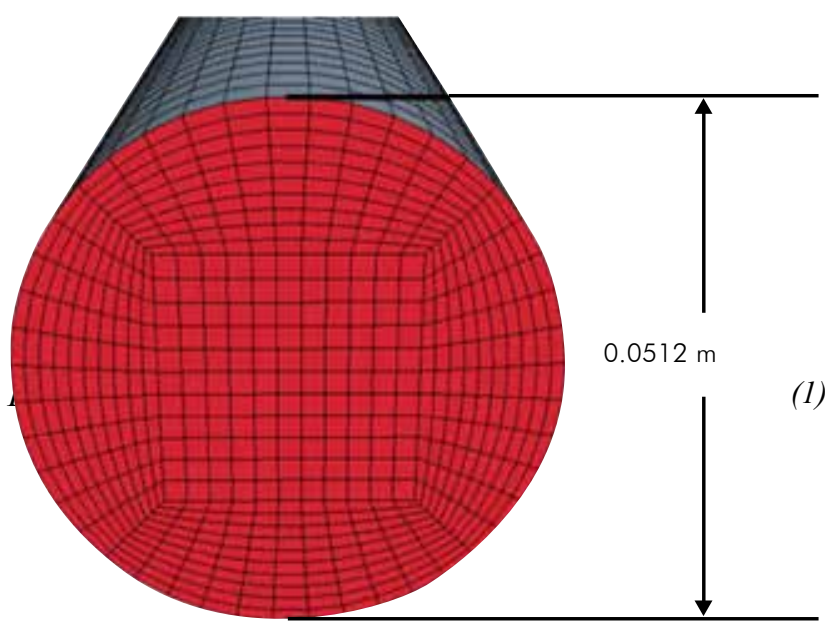

Figure 3. Orthogonal (Butterfly) grid

three boundary conditions. The inlet and outlet face were modeled with a velocity inlet and outlet pressure conditions, respectively. The surrounding face used a wall boundary condition. In addition, the mesh distribution was tested using a grid independence test to remove any mesh dependency in the system solution.

Two selection criteria were established in the grid independence test: resulting in accuracy and simulation time. The experiment case D was simulated with four grids that contained $43400,228780,312800$ and 415 140 mesh cells. As Eulerian and VOF models have a different mathematical formulation, previous tests were carried for each model to have the correct grid distribution for both models.

\section{Stability criterion}

Unsteady simulation was used to model the twophase flow dynamics. Consequently, the model stability depends strongly upon the time-step established. Convergence problems are present when the time-step is larger than velocity magnitude. The previous situation provokes the flow going through a large quantity of cells without solving intermediate points. As a consequence the CFD software brings up values to the intermediate points without solving the next interactions, in most of cases creating a diverge system (Abdulkadir, 2011). Due to the previous problem, the time-step is selected by the CFL criterion which uses the Courant number. The mathematical representation of this number is described in Equation (12).

$C=u_{G} \frac{\Delta t}{\Delta x}$

Where $\mathrm{C}$ is the Courant number $(\approx 0.25), \Delta t$ is the time-step and $\Delta x$ is the mesh cell size in direction of the maximum fluid velocity component. The velocity $u_{G}$ is calculated by the Drift-Flux model (Ujang et al., 2008) described in Equation (13).

$u_{G}=\left(1.2+\frac{0.8}{1+10 e^{-8} \operatorname{Re}_{s}^{2.55}}\right) u_{M}+0.35 \sqrt{g D}$

Where $\mathrm{g}$ is gravity, $R e_{s}$ is the Reynolds number for the liquid phase and $D$ is the pipe diameter. Based on the previous equations and the experiments description, a correct time-step is calculated to achieve a stable simulation.

\section{RESULTS AND ANALYSIS}

This section describes the results in two parts. The first section exposes the mesh independence tests results and describes the grid selected. The second part describes the two CFD models performance.

\section{Geometry meshing}

The simulation of the case D experiment was used to carry out the mesh independence test. Krepper et al. (2005) measured the void fraction using a sensor placed at $\mathrm{z} / \mathrm{D}=60$ with a flow inlet of $u_{g}=0.34 \mathrm{~m} / \mathrm{s}$ and $u_{l}=1.00 \mathrm{~m} / \mathrm{s}$. The average void fraction was 0.2618 with a standard deviation of $10 \%$. Results obtained by the VOF model and the Eulerian model are shown in Figure 4

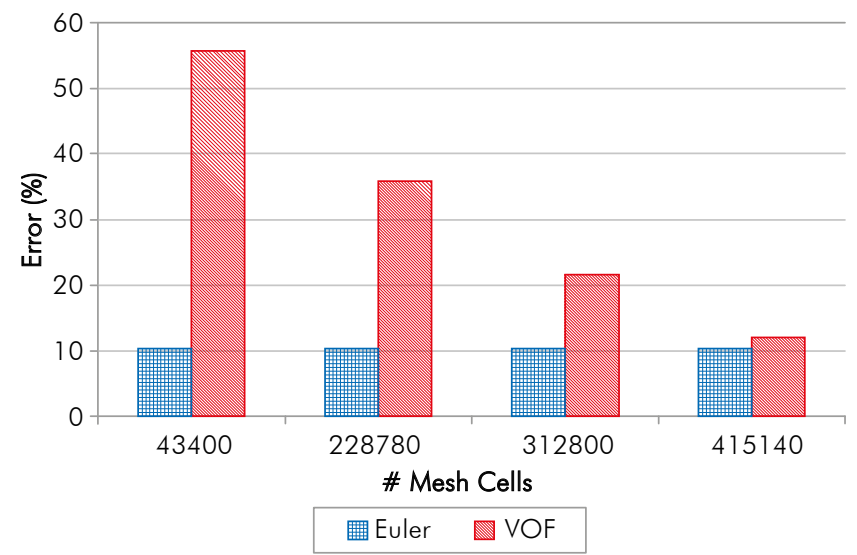

Figure 4. Mesh independence test - Experimental and CFD results comparison 
The VOF model in Figure 4 establishes that increasing the mesh cells number in the grid will decrease the error between the simulation and the experimental results. When considering the first selection criterion that standard deviation is $10 \%$ for the experimental result, only the grid with 415140 mesh cells could model the system correctly. On the other hand, the Eulerian model results demonstrate that resulted accuracy is not modified by the number of mesh cells. Furthermore, these results show that simulations with Eulerian model obtain an error equal to the standard deviation of the experimental results.

The second selection criterion for the grid is the simulation time. This parameter was analyzed using a one-node of the processor of an Intel ${ }^{\circledR}$ core-i5 computer with $6 \mathrm{~GB}$ of memory ram. The study's results are shown in Figure 5. It is evident that both models require more computer time if the number of mesh cells increase. Considering the previous results, the grid selected for the Eulerian model is the mesh with 43400 cells, as it reduces the simulation time without any effect in the accuracy of the results. On the contrary, the grid selected for the VOF model is the mesh with 415140 cells guaranteeing the accuracy of good results despite higher simulation time.

The simulation time spent by the Eulerian model and the VOF model is compared in Figure 5. The simulation studied requires 62000 inner interactions to complete the physical time established by the problem. This test proved that the Eulerian model always requires more simulation time than the VOF model. The reason for the previous result is that Eulerian model has more equations to solve than the VOF model. Furthermore, the Eulerian model is capable to predict the variable values in 40000 inner interactions. However, this new magnitude of interactions also requires more simulation time than the VOF model.

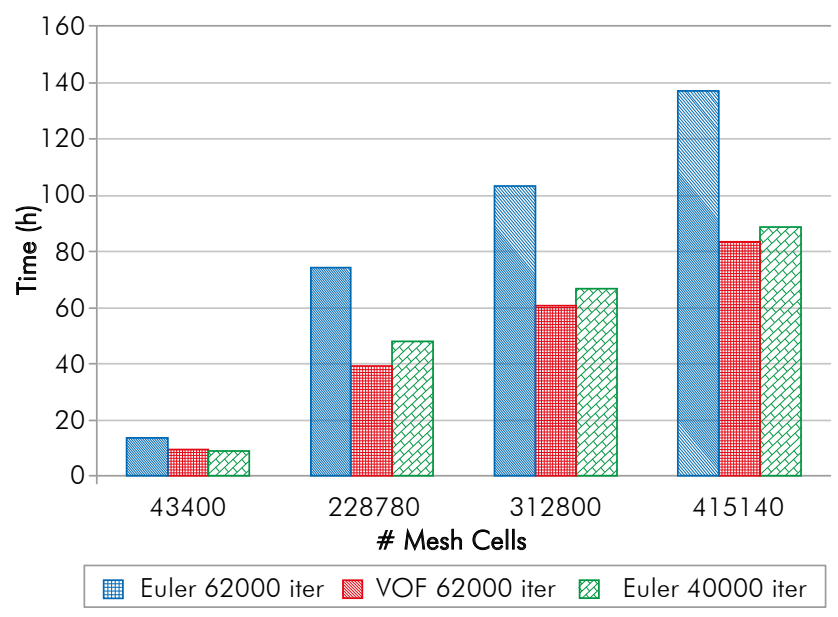

Figure 5. Mesh independence test - Simulation time

\section{Case studies}

The two-phase flow experiments described in Table 1 were simulated using the Eulerian model and the VOF model. Table 2 shows the results for cases A, B, C, and $\mathrm{D}$ in which the variable analyzed is the void fraction.

The cases $\mathrm{E}$ and $\mathrm{F}$ analyzed the total gas velocity and their results are shown in Table 2. Additionally, these tables show the experiment results obtained by the authors and the standard deviation of their experimentation. The simulation results demonstrate that the Eulerian model and the VOF model can describe

Table 2. Results of cases A, B, C and D using Eulerian model and VOF model

\begin{tabular}{|c|c|c|c|c|c|c|}
\hline \multirow{2}{*}{ Case } & \multirow{2}{*}{$a_{\text {experimental }}$} & \multirow{2}{*}{ Standard Deviation (\%) } & \multicolumn{2}{|c|}{ Eulerian } & \multicolumn{2}{|c|}{ VOF } \\
\hline & & & $a_{\mathrm{CFD}}$ & Error (\%) & $a_{C F D}$ & Error (\%) \\
\hline$A$ & 0.058 & 24.31 & 0.063 & 9.24 & 0.065 & 12.31 \\
\hline$B$ & 0.115 & 49.77 & 0.092 & 20.13 & 0.101 & 11.92 \\
\hline C & 0.196 & 46.42 & 0.165 & 15.61 & 0.118 & 39.86 \\
\hline $\mathrm{D}$ & 0.262 & 42.78 & 0.234 & 10.47 & 0.230 & 12.05 \\
\hline Case & $a_{\text {experimental }}$ & Standard Deviation (\%) & $\mathrm{u}_{G, C F D}$ & Error (\%) & $\mathrm{u}_{G, \mathrm{CFD}}$ & Error (\%) \\
\hline E & 17.038 & 8.72 & 12.203 & 28.38 & 12.223 & 28.26 \\
\hline $\mathrm{F}$ & 26.081 & 8.45 & 21.205 & 18.70 & 21.360 & 18.10 \\
\hline
\end{tabular}


correctly the two-phase flow with low void fractions. This fact is corroborated by the CFD results of cases A, B, C and D which are inside of the experimented standard deviations. On the contrary, both models showed errors higher than the standard deviation when simulating flows with higher void fractions.

Figure 6 shows the void fractions prediction of Eulerian and VOF models for cases A, B, C and D. The case $\mathrm{C}$ result for the VOF model shows an error higher than $30 \%$. Considering void fraction magnitude, the previous error is strongly significant. Therefore, the two-phase flow dynamics affects the accuracy of the VOF model. The best model selection criterion is the relative error which is calculated by the Equation (14). By modeling the low void fraction flow, the Eulerian model shows an error (13.86 \%) smaller than the VOF model (19.04\%). Additionally, both models obtain the same error $(\approx 23 \%)$ in the prediction of high void fraction flow.

$$
\text { Total Error }=\left[\frac{1}{N} \sum_{i=1}^{N}\left(\frac{x_{C F D i}-x_{\text {experimenta }_{i}}}{x_{\text {experimental }}}\right) * 100 \%\right.
$$

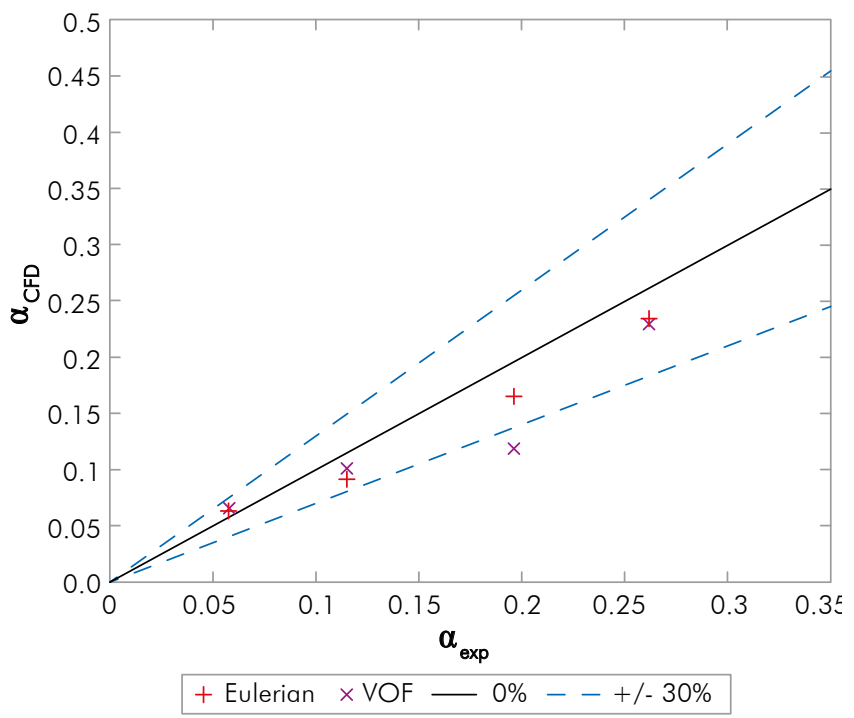

Figure 6. VOF model and Eulerian model predictions for cases A, B, C and D

The physical models differ in their mathematical formulation as it was explained in the theoretical background. This difference causes a distinct solution appearance for both models in spite of the similar variable

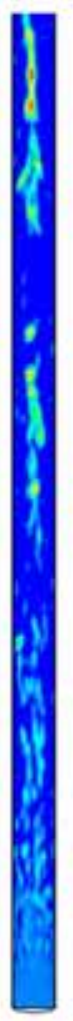

(a)

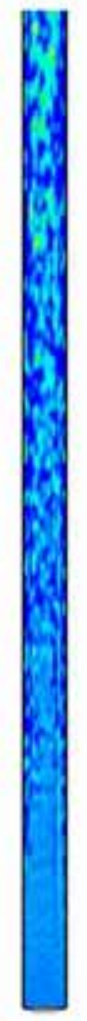

(b)

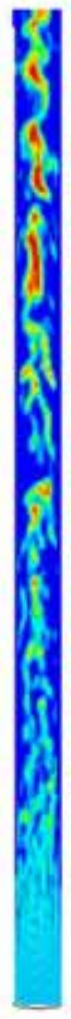

(c)

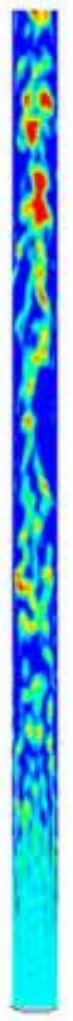

(d)

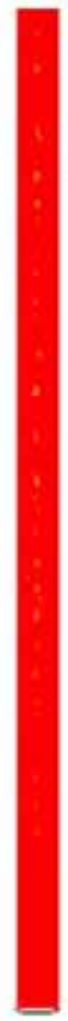

(e)

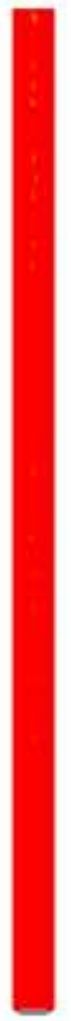

(f)

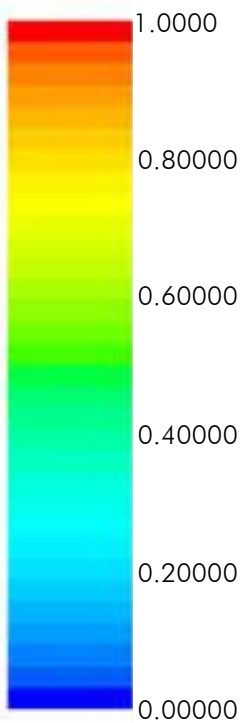

VOF Model

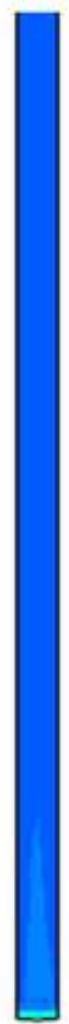

(a)

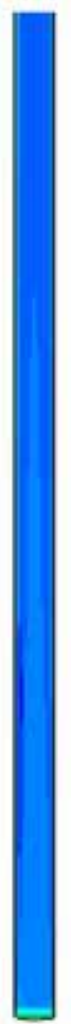

(b)

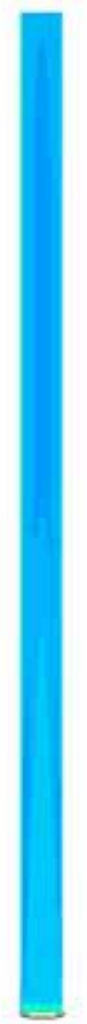

(c)

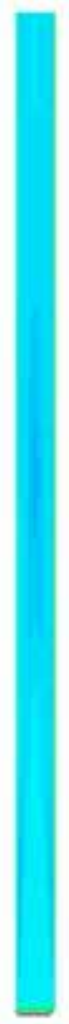

(d)

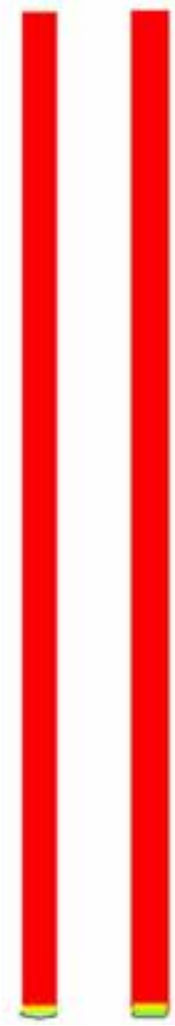

(e)

Figure 7. Void fraction for the cases studies by VOF model and Eulerian model (1.74 m of pipe) 
values that they obtained in the system's solution. The VOF model details better the bubbles in the two-phase flow than the Eulerian model, as shown in Figure 7. As an explanation, the VOF model solves the interface by the continuity of the equation as a function of the volume fraction, Equation (9), differentiating phase variables as none of the other equations distinguish phases. On the contrary, the Eulerian model does not solve the interface between liquid and gas phases. As a consequence, each cell has an average value for each variable. Hence, the Eulerian model solutions have a uniform color for the void fraction parameter. Moreover, Figure 7 shows that the VOF model is the correct physical model predicting the flow pattern.

The simulation results have a correct physical meaning considering that the case studies are organized in an ascendant manner according to the void fraction. The previous fact is corroborated in Figure 7. Additionally, as it was predicted in Figure 2, Figure 9 shows that cases $\mathrm{A}, \mathrm{B}, \mathrm{C}$, and D have a bubbly flow as the flow pattern, and cases $\mathrm{E}$ and $\mathrm{F}$ an annular pattern. However, the VOF model shows problems when modelling the liquid film between the wall and gas flows as caused by the mesh distribution. It is required to develop a more fineness mesh near the pipe wall to obtain this phenomenon.

\section{CONCLUSIONS}

CFD is a method capable to predict the dynamics of the gas-liquid two-phase flow. This project conducted a comparison between two CFD models in an upward flow. The methods studied are the Eulerian and VOF models. The first part evaluated the grid-model relations. The results demonstrated that the Eulerian model performance to predict the void fraction is irrelevant to the number of mesh cells in the grid. Moreover, the results exposed that Eulerian model requires more simulation time than the VOF model using the same grid. Nonetheless, the Eulerian model would spent less time if a grid with a low number of mesh cells is used, due to the mesh independency. The second part assessed the model prediction of the two-phase flow properties. In the bubbly flow, the Eulerian model is more accurate than VOF model by a difference of $5 \%$ in the void fraction prediction. On the other hand, both models showed problems when simulating the annular flow. Models accuracy may be increased by coupling new the CFD models. Opposite to the Eulerian model, the VOF model is capable of distinguishing the discontinuous and continuous phases in the solution appearance.

\section{ACKNOWLEDGEMENTS}

We would like to express our sincere gratitude to Siemens for all questions solved that supported the related research.

\section{REFERENCES}

Abdulkadir, M. (2011). Experimental and computational fluid dynamics (CFD) studies of gas-liquid flow in bends. $\mathrm{PhD}$ Thesis. University of Nottingham, Nottingham, England.

Ahmai, S. \& Al-Makky A. (2014). Simulation of two phase flow in elbow with problem solving. International Journal of Modern Physics C.

Anglart, H. \& Podowski, M. (2001). Mechanistic multidimensional modeling of slug flow-4th International Conference on Multiphase Flow.

Bratland, O. (2010). Pipe flow 2. Multi-phase flow assurance. Chonburi, Tailandia: Dr. Ove Bratland Flow Assurance Consulting.

Siemens. (2014). Documentation for STAR-CCM+. Siemens.

Da Silva, M. (2008). Impedance sensors for fast multiphase flow measurement and imaging. $\mathrm{PhD}$ Thesis. Technischen Universität Dresden.

Fang, C., David, M., Rogacs, A. \& Goodson, K. (2010). Volume of fluid simulation of the boiling two-phase flow in a vaporventing microchannel. Frontiers in Heat and Mass Transfer.

Hernandez, V., Abdulkadir, M. \& Azzopardi, B.J. (2010). Grid generation issues in the CFD modeling of the two-phase flow in a pipe. Journal of Computational Multiphase Flows, 3(1), 13-26.

Hewitt, G.F., Delhaye, J.M. \& Zuber, N. (1986). Multiphase science and technology (Volume 2). Springer-Verlag, Germany: Berlin. 
Ishii, M. \& Hibiki, T. (2011). Thermo-fluid dynamics of twophase flow (2nd Ed.). West Lafayette, U.S.A.: Springer.

Krepper, E., Lucas, D. \& Prasser, H. (2005). On the modeling of bubbly flow in vertical pipes. Nuclear engineering and design, 235, 597-611.

Krishna, R., Urseanu, M., van Baten, J. \& Ellenberger, J. (1999). Influence of scale on the hydrodynamics of bubble columns operating in the churn-turbulent regime: experiments vs. Eulerian simulations. Chemical Engineering Science. 54, 4903-4911.

Ratkovich, N., Majumder, S.K. and Bentzen, T.R. (2013). Empirical correlations and CFD siulations of vertical twophase gas-liquid (Newtonian and non-Newtonian) slug flow compared against experimental data of void fraction. Chemical Engineering Research and Design. 91, 988-998.

Shang, Z. (2015). A novel drag force coefficient model for gas-water two-phase flows under different flow patterns. Nuclear and Engineering and Design. 288, 208-219

Sharaf, S., Da Silva, M., Hampel, U., Zippe, C., Beyer, M. \& Azzopardi, BJ. (2011). Comparison between wire mesh sensor and gamma densitometry void measurements in two phase flows. Meas. Sci. Technol. 22(10).

Sharaf, S. \& Luna-Ortiz, E. (2014). Comparison between the two-phase models and wire mesh sensor measurements in medium and large diameter pipes. 14th AIChE Spring Meeting. New Orleans, U.S.A.

Sun, X., Paranjape, S., Kim, S., Ozar, B. \& Ishii, M. (2004). Liquid velocity in upward and downward air-water flows. Annals of Nuclear Energy, 31, 357-373.

Thome, J.R. (2004). Engineering Data book III. Lausanne Switzerland: Wolverine Tube, Inc.

Tkaczyk, P. (2011). CFD simulation of annular flows through bends. PhD Thesis. University of Nottingham, Nottingham, England.

Ujang, P.M., Pan, L., Manfield, P.D., Lawrence, C.J. \& Hewitt, G.F. (2008). Prediction of the translational velocity of liquid slugs in gas-liquid slug flow using computational fluid dynamics. Multiphase Science and Technology, 20(1), 25-79.
Van Der Meulen, G.P. (2012). Churn-annular gas-liquid flows in large diameter vertical pipes. $\mathrm{PhD}$ Thesis. University of Nottingham, Nottingham, England.

Wachem, B.G.M. \& Almstedt, A.E. (2003). Methods or multiphase computational fluid dynamics. Chemical Engineering Journal. 96, 81-98.

Westende, J.M.C. (2008). Droplets in annular-dispersed gas-liquid pipe-flows. PhD Thesis. Delft University of technology, Netherlands.

Woldesemayat, M. \& Ghajar, A. (2007). Comparison of void fraction correlations for different flow patterns in horizontal and upward inclined pipes. International Journal of Multiphase Flow, 33, 347-370.

Zhang, H.Q., Wang, Q., Sarica, C. \& Brill, J. (2003). Unified model for the gas-liquid pipe flow via slug dynamics-Part 1: Model development. Journal of Energy Resources Technology, 125, 266-273.

\section{AUTHORS}

\section{Esteban Guerrero}

Affiliation: Universidad de los Andes, Bogotá D.C., Colombia

e-mail: e.guerrero911@uniandes.edu.co

\section{Felipe Muñoz}

Affiliation: Universidad de los Andes, Bogotá D.C., Colombia e-mail: fmunoz@uniandes.edu.co

\section{Nicolás Ratkovich}

Affiliation: Universidad de los Andes, Bogotá D.C., Colombia. e-mail: n.rios262@uniandes.edu.co 


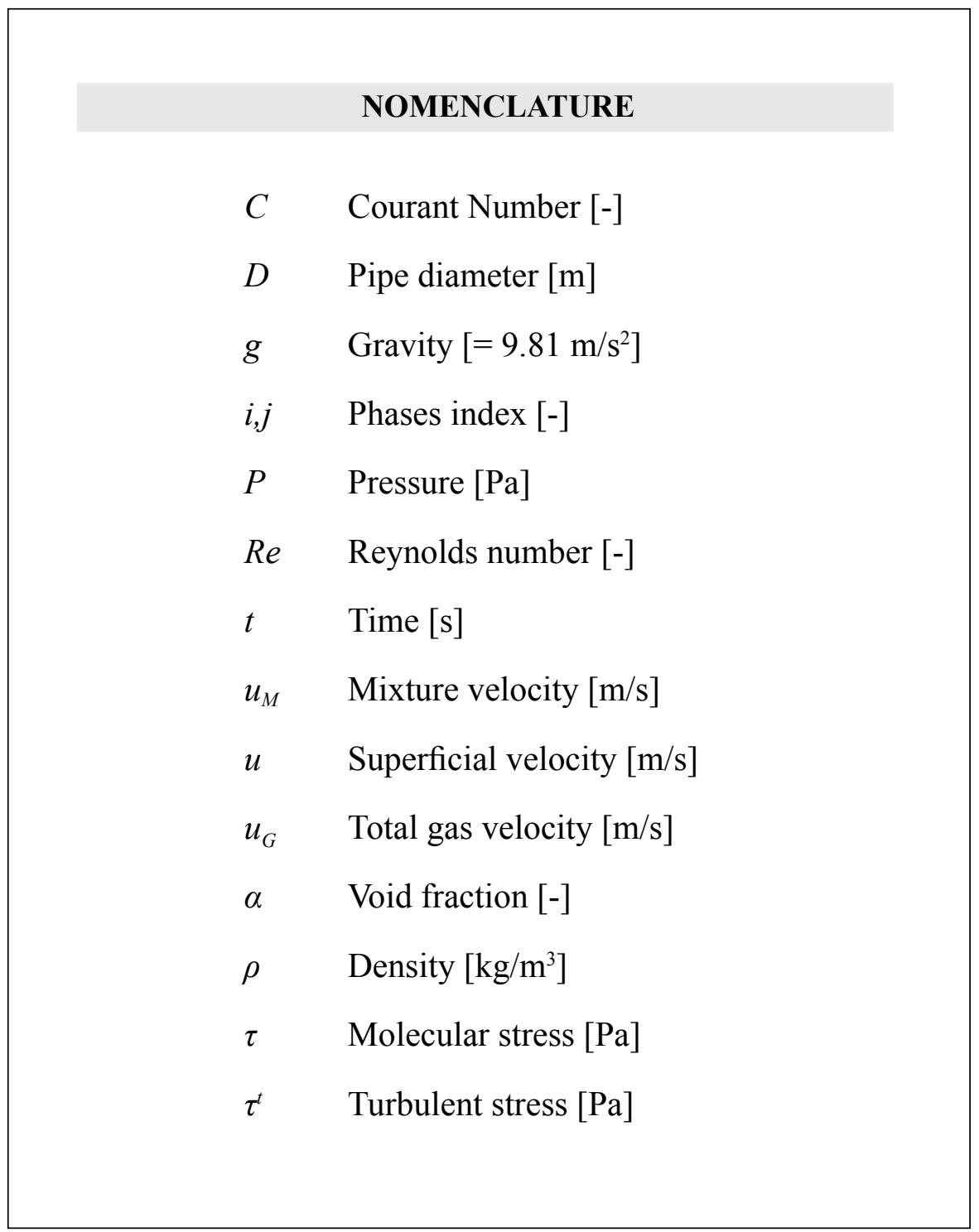

